Disponível em:

http://editora.unoesc.edu.br/index.php/race

RACE, Joaçaba, v. 16, n. 3, p. 209-234, edição especial, 2017

\title{
PROGRAMA DE MENTORIA: UMA ESTRATÉGIA SEMINAL DE COMPARTILHAMENTO DO CONHECIMENTO EM UMA EMPRESA PÚBLICA DE ENERGIA
}

Mentorial program: a seminal strategy of knowledge sharing in an public energy company

Lydia Maria Pinto Brito

E-mail: lydiampbrito@yahoo.com.br Doutora em Educação e Mestre em Sociologia pela Universidade Federal do Ceará;

Professora Titular na Universidade Potiguar.

Adaías Silvino da Silva

E-mail: lydiampbrito@yahoo.com.br Mestre em Administração pela Universidade Potiguar; Graduado em Administração pelas Faculdades Unificadas para Ensino das Ciências; Coordenador da área de Desenvolvimento de Sistemas da Empresa Automatech Tecnologia Comércio e Representações Ltda.

\section{Ahiram Brunni Cartaxo de Castro}

E-mail: brunnicastro@hotmail.com

Doutorando e Mestre em Administração pela Universidade Potiguar; Administrador no Instituto Federal de Educação, Ciência e Tecnologia do Rio Grande do Norte. Endereço para contato: Avenida Senador Salgado Filho, 1559, Tirol, 59015000, Natal, Rio Grande do Norte, Brasil.

Fernanda Fernandes Gurgel

E-mail: fernandafgurgel@hotmail.com Doutora em Psicologia pela Universidade Federal do Rio Grande do Norte com período sanduíche na Universidad Complutense de Madrid; Licenciada em Psicologia pela Universidade Federal do Rio Grande do Norte; Professora Adjunta na Universidade Federal do Rio Grande do Norte.

\section{Jedídja Hadassa de Santana Varela} E-mail: jhadassa2@gmail.com

Especialista em Psicologia Organizacional e do Trabalho e em Terapia Cognitivo-comportamental pela Universidade Federal do Rio Grande do Norte; Graduada em Psicologia pela Universidade Potiguar; Psicóloga no Centro Municipal de Reabilitação Infantil da Prefeitura Municipal de Parnamirim.

Artigo recebido em 06 de agosto de 2017. Aceito em 06 de novembro de 2017. 
Resumo

Neste estudo teve-se como objetivo analisar a percepção de mentores e mentorados de uma empresa pública de energia sobre o processo de compartilhamento do conhecimento, em um programa de mentoria implantado. Quanto à abordagem do problema, a pesquisa foi qualitativa com natureza descritiva. Seu modo de investigação foi o estudo de caso. O quadro de análise encontra-se no modelo de compartilhamento de conhecimento de Tonet e Paz (2006). Os resultados evidenciaram que as quatro fases do modelo teórico utilizado (iniciação, implementação, apoio e incorporação) apresentaram valores aceitáveis, sinalizandose pela existência de planejamento da demanda, interação entre mentores e mentorados, apoio do mentor ao mentorado no uso do conhecimento recebido e assimilação do conhecimento compartilhado e sua incorporação ao dia a dia de trabalho para a tomada de decisões sobre novos serviços, processos, tecnologias e produtos.

Palavras-chave: Gestão do Conhecimento. Compartilhamento do conhecimento. Mentoria. Empresa pública. Energia.

\section{Abstract}

This study aimed to analyze the perception of mentors and mentored of a public energy company about the process of knowledge sharing in an implemented mentoring program. Regarding the problem approach, the research was qualitative with a descriptive nature. His mode of investigation was the case study. The framework of analysis is found in the knowledge-sharing model of Tonet and Paz (2006). The results evidenced that the four phases of the theoretical model used (being initiation, implementation, support and incorporation) presented acceptable values, signaled by the existence of demand planning, interaction between mentors and mentored, support of the mentor to the mentored in the use of the knowledge received and the assimilation of shared knowledge and its incorporation into the day to day work for decision making about new services, processes, technologies and products.

Keywords: Knowledge management. Sharing knowledge. Mentoring. Public company. Energy.

\section{INTRODUÇÃO}

Em razão da importância assumida pela Gestão do Conhecimento (GC) frente à possibilidade de perda dos trabalhadores por meio de demissões, aposentadorias, afastamentos, remoções, entre outros, que incorre na perda de conhecimento, as organizações públicas passaram a adotar, no início dos anos 1990, programas de mentoria (mentoring) visando à retenção do seu principal ativo - propriedade intelectual - o conhecimento. 
O mentoring é uma ferramenta de gestão de pessoas em que o mentor ou tutor compartilha seu conhecimento e ajuda outrem (um jovem inexperiente ou novo trabalhador) a aprender algo que de outra maneira seria aprendido não tão bem, mais lentamente, ou de nenhuma maneira (BORGES; CARVALHO, 2013).

No Brasil, a mentoria tem sido disseminada lentamente e não tem se mostrado uma prática muito utilizada, inclusive pelas organizações públicas (SALGUES, 2016). Houve um estudo técnico realizado pela Secretaria de Fiscalização de Pessoal (Sefip) entre 2012 e 2013 em órgãos da Administração Pública Federal (APF), com o objetivo de avaliar a situação da governança e da gestão de pessoas em 330 organizações para identificar os pontos mais vulneráveis e induzir melhorias para as áreas de administração, agricultura, ciência e tecnologia, educação, energia, saúde, entre outras, nos diversos tipos de organizações (ministérios, autarquias e agências, estatais, instituições de ensino, militares, tribunais, entre outros); a mentoria, neste estudo, foi incluída como um desafio para a gestão de pessoas no serviço público. Foi possível perceber também que $77 \%$ das instituições públicas pesquisadas ainda não haviam publicado diretrizes para a GC, 63\% não executavam qualquer processo de GC, e 49\% não orientavam a força de trabalho em relação ao compartilhamento do conhecimento (TRIBUNAL DE CONTAS DA UNIÃO, 2013).

Estudos realizados por Quandt (2014) e Batista (2015) em organizações públicas da administração direta, sociedades de economia mista, empresas estatais, agências reguladoras, no Judiciário, no Legislativo, em fundações e autarquias, no Ministério Público concordaram que o mentoring está entre as práticas com menor alcance, sendo, portanto, uma prática utilizada em grau mais reduzido.

Nesse sentido, questiona-se: como é percebido o compartilhamento do conhecimento pelos mentores e mentorados de uma empresa pública de energia? O objetivo geral nesta pesquisa foi analisar a percepção de mentores e mentorados sobre o processo de compartilhamento do conhecimento em um programa de mentoria implantado. Os objetivos específicos foram verificar como ocorre a iniciação no processo de compartilhamento de conhecimento, conhecer como são estabelecidos os vínculos entre mentores e mentorados na implementação do processo de compartilhamento de conhecimento, identificar como acontece o apoio nas primeiras tentativas de aplicação do conhecimento compartilhado e verificar como acontece a incorporação do conhecimento compartilhado.

A organização estudada é uma empresa estatal internacional de energia que passou por um período de aproximadamente 10 anos, entre 1990 e 2000, realizando apenas admissões pontuais. Portanto, formou-se um hiato de 10 anos entre o tempo 
de serviço dos empregados mais experientes e o dos novatos. $\mathrm{O}$ vale existente atinge $52 \%$ de empregados com menos de 10 anos e 46\% com mais de 20 anos em uma das diretorias da empresa estudada no Nordeste do Brasil.

A concentração de conhecimento estratégico/crítico em alguns especialistas da organização, o elevado índice de potenciais aposentadorias desses técnicos mais experientes e o risco da saída desses técnicos despertou na organização a necessidade de adoção de um programa de gestão para reter o conhecimento que agrega valor.

Do ponto de vista acadêmico, o estudo veio contribuir desvelando a percepção de mentores e mentorados sobre o processo de compartilhamento do conhecimento em um programa formal de mentoria na visão daqueles que têm um papel fundamental no processo, mentores e mentorados.

\section{CONTEXTO TEÓRICO}

Vivencia-se na atualidade uma constante evolução na forma de se trabalhar, ancorada no conhecimento. Paradigmas são quebrados, e novos desafios surgem afetando o relacionamento entre as pessoas e as organizações. Dessa forma, as organizações passaram a adotar métodos formais de disseminação ou compartilhamento do conhecimento interno, entre eles a mentoria, para evitar que o conhecimento fique restrito a poucas pessoas, e que com a saída delas, a empresa venha a perder capital intelectual (TONET; PAZ, 2006).

Várias são as definições de mentoria, como as de Bell (2005, p. 3): "Mentoring é o ato de ajudar o outro a aprender", ou "Mentoring conjura a imagem de um sábio corporativo, experiente, conversando com um jovem inocente, inexperiente.” Porém, a definição de Kram (1988) é a mais clássica. Para esse autor, mentoria é um relacionamento entre duas pessoas, sendo uma mais velha, experiente, digna de respeito e confiança, denominada mentor; e outra pessoa mais jovem, inexperiente e ávida por receber conhecimento, conselhos e orientações, denominada mentorado. Com um enfoque diferente, a mentoria reversa acontece quando jovens técnicos ensinam executivos mais velhos, por exemplo, no caso das tecnologias da informação (MONTE, 2011).

A mentoria formal é um processo planejado e executado pela organização, com metas bem-definidas e com o objetivo de reter talentos, transmitir valores, perpetuar a cultura, formar sucessores, desenvolver carreiras e compartilhar o conhecimento tácito de seus empregados, para, assim, manter o conhecimento no ambiente interno e aumentar seu capital intelectual (KRAM, 1988). 
Nesse sentido, Kram (1988) definiu um modelo conceitual de mentoria voltado ao apoio e à orientação a ser desenvolvido por um mentor, distribuído em duas categorias: funções de carreira (no decorrer da sua execução possibilitam a interação do mentorado com pessoas da organização que poderão no futuro ser responsáveis pelo avanço em sua carreira) e funções psicossociais (cujos aspectos dizem respeito ao relacionamento interpessoal).

Kram (1988) antecedeu vários autores como Noe; Bellodi e Martins; Allen, Eby e Lentz; Griffin, Colella e Goparaju; Chao, Walz e Gardner; Lahti; Brown, Darly e Leong; Souza; Ragins e Cotton; Feldman; Russel e Adams; Bernhoeft; Scandura; Monte; Shea; Guptan; Montenegro; Borges, Wang e Noe, entre outros, que contribuíram ao longo do tempo uma perspectiva evolutiva do assunto sobre:

a) as funções da mentoria ou tutorização;

b) a historicidade da prática;

c) a noção de mentoria ou tutorização informal e formal;

d) a usabilidade da mentoria na educação, na residência médica e na construção civil;

e) a mentoria como função de apoio e suporte psicossocial e feedback;

f) como função de estímulo ao crescimento da carreira dos mentorados;

g) o papel dos mentorados como sujeitos ativos no processo;

h) avaliação de programas de mentoria;

i) as habilidades necessárias para o exercício da tutoria;

j) a cultura organizacional e a estrutura organizacional para o compartilhamento do conhecimento;

k) os fatores motivadores do compartilhamento do conhecimento;

1) a avaliação das expectativas do iniciante para preparar colegas e líderes (NOE, 1988; SCANDURA, 1998; LAHTI; BEYERLEIN, 2000; BERNHOEFT, 2001; SHEA, 2001, 2003; BORGES; ALBUQUERQUE, 2004; GUPTAN, 2006; MONTE, 2011; SCULLY; KHOSROWSHAHI, 2011; WANG; NOE, 2010; BORGES; CARVALHO, 2013). 
No entanto, a temática da mentoria tem acompanhado por longo período, principalmente na literatura sobre gestão de pessoas, as publicações sobre socialização organizacional (BORGES; CARVALHO, 2013).

Atualmente, no contexto da gestão de pessoas na sociedade do conhecimento, a função clássica desenvolvimento, que normalmente coordena a mentoria, tem sido ressignificada para disseminação/competências, criação de comunidades de aprendizagem e retenção do conhecimento do trabalhador (propriedade intelectual) (BRITO, 2005; MARQUES, 2015; CASTRO; BRITO; VARELA, 2017).

Portanto, se enquanto subsistema de gestão de pessoas o foco era no indivíduo, no cargo ou na tarefa, atualmente o foco está no desenvolvimento das competências profissionais. Os trabalhadores não ditam mais suas necessidades de capacitação, pois a organização por meio do perfil ou trilha de competências profissionais é quem direciona a educação dos trabalhadores. E uma das estratégias utilizadas pelas organizações, por exemplo, são as universidades corporativas, pois se configuram como centros de qualificação profissional com foco no desenvolvimento do trabalhador para o trabalho, fugindo da lógica tradicional das universidades públicas e privadas de preparação para o mercado de trabalho (FREIRE et al., 2016; CASTRO; BRITO; VARELA, 2017).

De modo geral, nesse novo contexto (da ressignificação), conforme Strauhs et al. (2012), Kianto et al. (2014) e Freire et al. (2016), a educação para o trabalho se configura como a espinha dorsal da gestão do trabalho com pessoas, tornando-se uma questão estratégica para as organizações, pois passa a ser o processo viabilizador para a transformação do conhecimento tácito dos trabalhadores em conhecimento explícito, além de ser o processo criador de novos conhecimentos e de inovação contínua. Já o processo típico dos trabalhadores passa a ser o de disseminador, compartilhador, networker (articulador de redes de contatos), auxiliar e mentor (FUKUNAGA et al., 2015; OLIVEIRA; CASTRO; BRITO, 2016).

No contexto atual das publicações na área de administração sobre a temática, o estado da arte repousa sobre a mentoria como uma estratégia de iniciação ao trabalho de novos trabalhadores (REALI; TANCREDI; MIZUKAMI, 2010), uma tendência integradora de socialização organizacional (ANDRADE et al., 2012), uma atividade em rede para o desenvolvimento de carreiras empreendedoras (BRUNO-FARIA; VARGAS, 2013), uma forma de assegurar feedback no ambiente de trabalho (TROTTA et al., 2014), uma estratégia de sucessão em empresas familiares (SILVA; SOUZA-SILVA, 2015; BOZIONELOS et al., 2016), uma estratégia de construção de confiança mútua, influência e aprendizagem contínua (BELO; ACCIOLY, 2015; ALMEIDA; SOUZA-SILVA, 2015), como a principal atividade responsável pelo de- 
senvolvimento de habilidades interpessoais (DOS-SANTOS et al., 2015), uma estratégia formal de disseminação do conhecimento (SALGUES, 2016), uma estratégia de inclusão social (PORTUGAL, 2016), uma estratégia para o desenvolvimento de competências gerenciais (BRITO-DE-JESUS et al., 2014), entre outras.

Pode ser aplicada em uma variedade de contextos, como: nos seguimentos de varejo, entretenimento e centros de saúde (STRAUS et al., 2013; BELO; ACCIOLY, 2015), incubadoras tecnológicas (BRUNO-FARIA; VARGAS, 2013), micro e pequenas empresas (SILVA; SOUZA-SILVA, 2015; BOZIONELOS et al., 2016), além de universidades públicas (ALBANAES; SOARES; BARDAGI, 2015) e empresas públicas (SANTOS, 2015).

Em seguida, tem-se a trilha metodológica utilizada para a consecução da pesquisa.

\section{PROCEDIMENTOS METODOLÓGICOS}

Quanto ao modo de investigação, a pesquisa foi classificada como um estudo de caso de abordagem qualitativa e de natureza descritiva, em que se busca uma descrição intensiva e análise de um fenômeno, processo ou unidade social com um indivíduo, grupo, instituição ou comunidade (GODOY, 1995; MERRIAM, 1998; YIN, 2010; VERGARA, 2011). Utilizou-se como quadro de análise o modelo de compartilhamento do conhecimento proposto por Tonet e Paz (2006).

A escolha desse modelo ocorreu por se tratar de uma das principais referências do programa implantado na empresa pública estudada.

O modelo de compartilhamento do conhecimento de Tonet e Paz (2006) tem como objetivo auxiliar no entendimento sobre o que acontece quando pessoas compartilham conhecimento no trabalho, e está ancorado na teoria de sistemas de Bertalanfly (1975). É composto por quatro fases (iniciação, implementação, apoio e incorporação) e baseai-se em quatro elementos básicos análogos ao processo (fonte do conhecimento, destinatário, conhecimento a ser compartilhado e contexto em que o compartilhamento ocorre). 
Esquema 1 - Modelo de compartilhamento do conhecimento

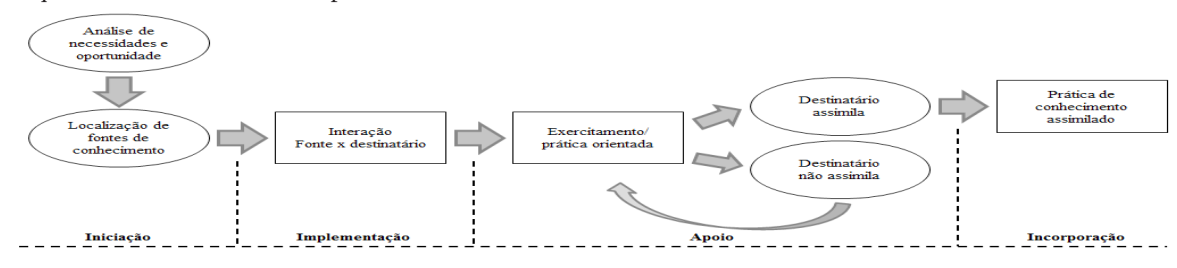

Fonte: adaptado de Tonet e Paz (2006, p. 81).

A fase de iniciação é responsável pela identificação de necessidades ou demandas de conhecimento. A de implementação tem como ponto central as trocas que ocorrem entre a fonte e o destinatário do conhecimento, bem como as condições nas quais as trocas acontecem. É nessa fase que são estabelecidos os vínculos entre o repassador (mentor) e o recebedor (mentorado) do conhecimento.

Na fase de apoio o foco principal reside no esclarecimento de pontos de atenção sobre o conhecimento que não foi repassado com êxito e que, se usado, poderá alcançar os resultados esperados. A fase de incorporação envolve a aplicação prática do conhecimento recebido no contexto de trabalho, com destaque para a inserção do conhecimento na execução das atividades por um número maior de pessoas.

Quanto ao universo desta pesquisa, pretendia-se realizar um censo com os 43 empregados de uma diretoria específica da organização estudada no Nordeste do Brasil, visto que 37 responderam ao questionário elaborado por meio do modelo proposto, somando-se uma amostra de 86\% do universo. Segundo Merriam (1998), um pequeno grupo de sujeitos é selecionado porque o pesquisador quer compreendê-lo em profundidade, não encontrar formas de generalizar os achados para a população.

Para a consecução da pesquisa, foram executados os passos a seguir:

a) inicialmente os autores elaboraram dois questionários a partir do modelo de compartilhamento do conhecimento proposto por Tonet e Paz (2006), um para os mentores e outro para os mentorados;

b) os questionários foram validados pela coordenadora do programa de mentoria da organização pesquisada, por pares (colegas de trabalho), e em seguida, por auditores externos/juízes (professores da área de uma universidade privada), para garantir a confiabilidade dos instrumentos e a ética na pesquisa; 
c) realizados ajustes finais, nos quais o questionário dos mentores foi composto por 34 perguntas, divididas em quatro seções, sendo quatro perguntas na seção sociodemográfico, 11 perguntas na seção iniciação, 14 na implementação e cinco na seção de apoio. Já o questionário dos mentorados foi composto por 51 perguntas divididas em cinco seções, com quatro perguntas na seção sociodemográfico, 11 perguntas na seção iniciação, 16 na implementação, nove na seção de apoio e 11 na seção de incorporação. Em ambos os questionários, as perguntas do perfil sociodemográfico foram as mesmas. Observou-se que o questionário dos mentores não possuía a seção incorporação, visto que esta é voltada para a aplicação do compartilhamento do conhecimento, sendo, no caso em estudo, aplicado apenas para os mentorados. Foi utilizada uma escala ordinal Likert para estabelecer uma graduação de atitudes em que os números indicam as posições relativas de compreensão dos pesquisados sobre o fenômeno (LIKERT, 1932; GABRIEL, 2014);

d) os questionários foram enviados pela coordenadora do programa de mentoria da organização pesquisada para os respondentes via aplicação de tecnologia da informação.

Para a interpretação dos dados, quanto maior for a pontuação, melhor será o compartilhamento do conhecimento. Utilizaram-se planilhas eletrônicas para o tratamento dos dados, momento em que foi estabelecido o Ranking Médio (RM) proposto por Malhotra (2001) para mensurar o grau de concordância dos pesquisados.

O RM de cada questão é obtido mediante a soma dos valores de cada item avaliativo dividido pelo total de respondentes de cada questão.

n = Número da questão; $\mathrm{f}(\mathrm{n})=$ Frequência absoluta dos respondentes da questão (n); RM = Ranking Médio; RM(n) = f1(n) x 1 + f2(n) x 2 + f3 x 3 + f4(n) x 4 + $\mathrm{f} 5(\mathrm{n}) \times 5 /(\mathrm{f} 1(\mathrm{n})+\mathrm{f} 2(\mathrm{n})+\mathrm{f} 3(\mathrm{n})+\mathrm{f} 4(\mathrm{n})+\mathrm{f} 5(\mathrm{n}))$

Com base no RM das respostas foi analisada a aceitabilidade ou não dos itens avaliados. Para valores de RM menores que três se consideram como não aceitáveis e maiores que três como aceitáveis. O RM igual a três é avaliado como neutro. Foi analisado também o percentual de concordantes de cada pergunta dos questionários, levando-se em consideração as respostas (concordo parcialmente e concordo total- 
mente) em relação às demais. Consideram-se como aceitáveis, a partir de critérios da empresa pública estudada, valores acima de $70 \%$. O cálculo é efetuado da seguinte forma:

Concordante $=$

$$
\mathrm{CP}+\mathrm{CT}
$$

$$
\mathrm{DT}+\mathrm{DP}+\mathrm{NCND}+\mathrm{CP}+\mathrm{CT}
$$

$\mathrm{CP}=$ Concordo Parcialmente; $\mathrm{CT}=$ Concordo Totalmente; NCND $=$ Nem Concordo Nem Discordo; DP = Discordo Parcialmente; DT = Discordo Totalmente

Na sequência, estão descritos e discutidos os resultados da pesquisa.

\section{MENTORIA SEGUNDO SEUS ATORES}

A partir dos resultados da pesquisa, foi possível perceber quanto à caracterização dos respondentes, que a maioria, tanto mentores quanto mentorados, é do sexo masculino. No caso dos mentores, a maioria dos respondentes possui em média mais de 21 anos de trabalho na instituição, com pós-graduação (mestrado ou doutorado), e ocupa a função de consultor. No caso dos mentorados, a maioria deles possui até 10 anos de empresa, com escolaridade em nível superior e não ocupa funções de confiança.

Conforme o modelo proposto por Tonet e Paz (2006), foi possível diagnosticar o compartilhamento de conhecimento analisando-se as fases que constituem o modelo. Dessa forma, estão apresentados nas Tabelas 1 e 2 os valores referentes aos dados obtidos e tratados para a realização de sua análise.

\begin{tabular}{|c|c|c|}
\hline Fases & $\mathbf{R M}$ & Concordantes \\
\hline Iniciação & 4,5 & $90 \%$ \\
\hline Implementação & 4,1 & $76 \%$ \\
\hline Apoio & 4,4 & $89 \%$ \\
\hline
\end{tabular}

Tabela 1 - Percepção dos mentores 
Tabela 2 - Percepção dos mentorados

\begin{tabular}{lcrr}
\hline \multicolumn{1}{c}{ Fases } & RM & & Concordantes \\
\hline Iniciação & 4,3 & $84 \%$ \\
Implementação & 4,1 & $82 \%$ \\
Apoio & 4,2 & $82 \%$ \\
Incorporação & 4,0 & $74 \%$ \\
\hline Fonte: os autores. & &
\end{tabular}

De acordo com as Tabelas 1 e 2, observa-se que, tanto para mentores quanto para mentorados, o RM de todas as fases ficou acima de 3 e os percentuais de concordantes, acima de 70\%. Conforme Malhotra (2001), para um grau de concordância dos pesquisados maior que 3 ou percentual de concordantes (concordo parcialmente + concordo totalmente) maior que $70 \%$ os resultados foram considerados aceitáveis. Conclui-se, portanto, com base no modelo de Tonet e Paz (2006), que os resultados da pesquisa demonstraram um bom desempenho e valores aceitáveis para o compartilhamento de conhecimento no programa de mentoria implementado.

Os valores de RM de todas as fases foram superiores a três, provavelmente por se tratar de uma organização que é referência na gestão de conhecimento, na qualificação dos trabalhadores, sendo, inclusive, ganhadora de prêmio na área.

\subsection{DIAGNÓSTICO DA FASE DE INICIAÇÃO}

Conforme apresentado nas Tabelas 1 e 2, os valores de 4,5 para RM e de $90 \%$ de concordantes para os mentores, de 4,3 para RM e de $84 \%$ de concordantes para os mentorados, na fase de iniciação, representaram o melhor resultado entre todas as fases, tanto para os mentores quanto para os mentorados. Os resultados demonstraram que foi realizado um bom planejamento do programa de mentoria na organização estudada, ao se escolher o conhecimento compartilhado, vinculado à estratégia, e, também, ao selecionar os mentores e os mentorados com as competências desejáveis, já que Tonet e Paz (2006) afirmam que as principais dificuldades da fase de iniciação estão em localizar demandas existentes, localizar as fontes aptas e disponíveis para repassar o conhecimento e mapear e desenvolver as competências requeridas. Embora o resultado da pesquisa para essa fase tenha sido elevado, foi importante destacar os fatores que mais contribuíram, bem como aqueles que menos contribuíram e, portanto, necessitaram de uma melhor atenção, conforme a Tabela 3. 


\begin{tabular}{|c|c|c|c|c|}
\hline \multirow[b]{2}{*}{ Fator } & \multicolumn{2}{|c|}{ Mentor } & \multicolumn{2}{|c|}{ Mentorado } \\
\hline & $\mathbf{R M}$ & $\begin{array}{l}\text { Concor- } \\
\text { dantes }\end{array}$ & $\mathbf{R M}$ & $\begin{array}{l}\text { Concor- } \\
\text { dantes }\end{array}$ \\
\hline $\begin{array}{l}\text { Conhecimento compartilhado, fazer parte da estratégia } \\
\text { da organização. }\end{array}$ & 4,9 & $100 \%$ & 4,4 & $82 \%$ \\
\hline $\begin{array}{l}\text { Domínio sobre o conhecimento técnico transmitido } \\
\text { (compartilhado). }\end{array}$ & 4,8 & $100 \%$ & & \\
\hline Habilidade de comunicação e relacionamento. & 4,7 & $93 \%$ & & \\
\hline $\begin{array}{l}\text { Conhecimento compartilhado vinculado as atividades } \\
\text { cotidianas. }\end{array}$ & & & 4,8 & $100 \%$ \\
\hline Conhecimento compartilhado não era do inteiro domínio. & & & 4,5 & $91 \%$ \\
\hline Motivação. & & & 4,5 & $91 \%$ \\
\hline
\end{tabular}

O fator que mais contribuiu nessa fase foi a percepção de que o conhecimento compartilhado faz parte da estratégia da organização, avaliado pelos mentores com RM de 4,9 e percentual de concordantes de 100\%. Também para os mentorados esse fator apresentou números expressivos com RM de 4,4 e percentual de concordantes de $82 \%$. Os resultados obtidos denotaram que a organização acertou ao decidir reter o conhecimento de valor que residia apenas em alguns especialistas, conhecimento este crítico e estratégico para a manutenção da organização no mercado.

Outro fator que também contribuiu de forma significativa na fase de iniciação, segundo a percepção dos mentores, foi o domínio do conhecimento técnico transferido (compartilhado) que eles possuem, com RM de 4,8 e percentual de concordantes de $100 \%$. Os bons resultados alcançados nessa fase foram relacionados ao fato de a empresa pesquisada ter no seu quadro de mentores profissionais com perfil de consultor - função atribuída ao empregado que demonstra requisitos de excelência em conhecimento, experiência e competência técnica, demonstrando-se que o processo típico dos trabalhadores mentores da empresa pública pesquisada passou a ser o de disseminador, compartilhador, networker, auxiliar e mentor (FUKUNAGA et al., 2015; OLIVEIRA; CASTRO; BRITO, 2016).

Já em relação aos mentorados, o fator "Conhecimento compartilhado vinculado às atividades cotidianas”, com ranking médio de 4,8 e percentual de concordan- 
tes de $100 \%$, obteve o maior resultado. Concorreu para expressividade dos números o fato de o conhecimento compartilhado no programa de mentoria estar diretamente ligado às atividades do mentorado. A organização definiu o conhecimento compartilhado, selecionou os mentores que detinham o conhecimento e os mentorados que possuíam um gap desse conhecimento para o desempenho das suas atividades.

Tabela 4 - Fatores que menos contribuíram na fase de iniciação

\begin{tabular}{|c|c|c|c|c|}
\hline \multirow[b]{2}{*}{ Fator } & \multicolumn{2}{|c|}{ Mentor } & \multicolumn{2}{|c|}{ Mentorado } \\
\hline & $\mathbf{R M}$ & $\begin{array}{l}\text { Concor- } \\
\text { dantes }\end{array}$ & $\mathbf{R M}$ & $\begin{array}{l}\text { Concor- } \\
\text { dantes }\end{array}$ \\
\hline $\begin{array}{l}\text { Organização possui uma cultura que propicia o comparti- } \\
\text { lhamento de conhecimento. }\end{array}$ & 3,8 & $80 \%$ & 3,9 & $82 \%$ \\
\hline $\begin{array}{l}\text { Consultar previamente sobre os assuntos que devem ser } \\
\text { compartilhados. }\end{array}$ & & & 3,6 & $68 \%$ \\
\hline
\end{tabular}

Entre os fatores que menos contribuíram na fase de iniciação, o fator “A organização possui uma cultura que propicia o compartilhamento de conhecimento" obteve o maior valor, com RM de 3,8 e percentual de concordantes de $80 \%$ entre os mentores, e RM de 3,9 e percentual de concordantes de $82 \%$ entre os mentorados. O resultado obtido pôde ser explicado considerada a estrutura organizacional, pois a empresa pública pesquisada possui uma estrutura hierárquica "militar” que favorece a centralização das decisões e ainda mantém condutas tayloristas-fordistas, sendo, portanto, antagônica às estruturas matriciais e horizontais que possuem decisões descentralizadas e sistemas de cooperação.

\subsection{DIAGNÓSTICO DA FASE DE IMPLEMENTAÇÃO}

Em relação à fase de implementação, como se observa na Tabela 5, o resultado do RM, tanto de mentores quanto de mentorados, apresentou o mesmo valor, 4,1. No entanto, o percentual de concordantes dos mentorados de $82 \%$ foi superior aos concordantes de mentores de 76\%. Os resultados apurados encontraram-se acima da média, demonstrando que as trocas ocorridas por meio da interação entre mentor e mentorado, bem como as condições em que o compartilhamento de conhecimento ocorreu, aconteceram conforme o planejado para o programa de mentoria implementado. 
Tabela 5 - Fatores que mais contribuíram na fase de implementação

\begin{tabular}{|c|c|c|c|c|}
\hline \multirow{2}{*}{ Fator } & \multicolumn{2}{|c|}{ Mentor } & \multicolumn{2}{|c|}{ Mentorado } \\
\hline & $\mathbf{R M}$ & Concordantes & $\mathbf{R M}$ & Concordantes \\
\hline Habilidade de comunicação (Destinatário). & 4,9 & $100 \%$ & & \\
\hline Relação de confiança. & 4,8 & $93 \%$ & 4,6 & $100 \%$ \\
\hline $\begin{array}{l}\text { Não houve resistência do mentorado em adquirir } \\
\text { o conhecimento. }\end{array}$ & 4,6 & $93 \%$ & & \\
\hline Domínio do conhecimento transmitido (Fonte). & & & 4,7 & $100 \%$ \\
\hline Habilidade de comunicação (Fonte). & & & 4,5 & $86 \%$ \\
\hline
\end{tabular}

Fonte: os autores.

Em relação aos fatores que mais contribuíram nessa fase, destacou-se a habilidade de comunicação de mentores e mentorados. Os mentores avaliaram os mentorados com RM de 4,9 e percentual de concordantes de $100 \%$, enquanto os mentorados avaliaram os mentores com RM de 4,5 e percentual de concordantes de $86 \%$. Conforme relatado na análise da fase de iniciação, mentores e mentorados não foram escolhidos com base nas suas habilidades de comunicação, mas no conhecimento que deveria ser repassado e recebido, porém a alta capacidade técnica, a escolaridade elevada e o treinamento que foi realizado pela organização na fase de preparação dos mentores e mentorados contribuíram para os números positivos obtidos nessa fase, revelando-se que o programa de mentoria implantado tinha entre suas principais forças o desenvolvimento de habilidades interpessoais, corroborado por Dos-Santos et al. (2015).

Outro fator que contribuiu para os bons resultados nessa fase foi a relação de confiança, em que os mentores avaliaram com RM de 4,8 e percentual de concordantes de $93 \%$, e os mentorados avaliaram com RM de 4,6 e percentual de concordantes de $100 \%$. A seleção do conhecimento a ser compartilhado no programa de mentoria proporcionou a seleção de mentorados e mentores que trabalhavam na mesma atividade, ou seja, mentores e mentorados já se conheciam e trabalhavam juntos anteriormente à implementação do programa de mentoria. Essa particularidade contribuiu para potencializar os resultados do fator laços de confiança entre mentores e mentorados, conforme teoriza Guptan (2006), Belo e Accioly (2015) e Almeida e Souza-Silva (2015), pois, do contrário, a falta de confiança poderia ser uma barreira ao compartilhamento de conhecimento na medida em que geraria distorções na comunicação entre receptor e emissor. 
Outro fator de destaque na percepção dos mentores foi o de não haver resistência do mentorado em adquirir o conhecimento, com RM de 4,6 e percentual de concordantes de 93\%. Na percepção dos mentores não houve, por parte dos mentorados, temor em assimilar o conhecimento, e por já trabalharem, ainda que de forma embrionária, em suas atividades, com os conhecimentos transferidos, não houve medo da mudança na forma de trabalhar. Esses resultados estão de acordo com o pensamento de Tonet e Paz (2006), que trazem que a resistência do destinatário em adquirir o conhecimento advém do medo em não assimilar a nova aprendizagem, ou de o destinatário não estar disposto a mudar a forma como trabalha.

Tabela 6 - Fatores que menos contribuíram na fase de implementação

\begin{tabular}{|c|c|c|c|c|}
\hline \multirow{2}{*}{ Fator } & \multicolumn{2}{|c|}{ Mentor } & \multicolumn{2}{|c|}{ Mentorado } \\
\hline & $\mathbf{R M}$ & Concordantes & $\mathbf{R M}$ & Concordantes \\
\hline Sobrecarga de atividades. & 2,9 & $40 \%$ & 3,2 & $55 \%$ \\
\hline $\begin{array}{l}\text { Trabalhar antecipadamente problemas já } \\
\text { conhecidos. }\end{array}$ & 3,5 & $47 \%$ & & \\
\hline $\begin{array}{l}\text { Forma dos encontros (Reunião presencial, } \\
\text { videoconferência). }\end{array}$ & 3,7 & $60 \%$ & 3,9 & $73 \%$ \\
\hline Avaliação do programa. & & & 3,6 & $73 \%$ \\
\hline Mentoria reversa. & & & 3,8 & $73 \%$ \\
\hline
\end{tabular}

Em relação aos fatores que menos contribuíram na fase de implementação, o fator de pior desempenho, tanto para os mentores quanto para os mentorados, foi a sobrecarga de atividades com RM de 2,9 e percentual de concordantes de $40 \%$ para os mentores; e 3,2 de RM e percentual de concordantes de 55\% para os mentorados. Esse resultado possivelmente esteve atrelado à dificuldade de conciliar as atividades cotidianas com os encontros de mentoria, podendo, ainda, estar relacionado à dispersão geográfica da organização e ao regime de trabalho. Portanto, apesar de os mentores e mentorados estarem cientes dos benefícios da partilha de conhecimentos, eles encontraram dificuldade em relação ao tempo disponível para implementá-la.

Outro fator que apresentou baixo desempenho para os mentores foi trabalhar antecipadamente problemas já conhecidos, com RM de 3,5 e percentual de concordantes de 47\%. Conforme Tonet e Paz (2006), deve-se ter cuidado com a recorrência de problemas já conhecidos, que poderão afetar a disposição e o interesse tanto da 
fonte quanto do destinatário do conhecimento. No caso em estudo, não foi possível tratar esse problema em razão de o programa de mentoria implantado ser seminal.

Em relação ao fator forma dos encontros (reunião presencial, videoconferência), os resultados foram baixos para os mentores, com RM de 3,7 e percentual de concordantes de $60 \%$, e também para os mentorados, com RM de 3,9 e percentual de concordantes de $73 \%$. Os resultados revelaram que a estrutura definida no planejamento para os encontros não foi totalmente aceita. Por se tratar de um compartilhamento de conhecimento tácito, em que se faz necessário o contato face a face entre mentor e mentorado, uma estratégia inadequada na forma dos encontros pode ter comprometido a eficácia do programa de mentoria. Os resultados estiveram consonantes com Tonet e Paz (2006), que reforçam a necessidade de condições estruturais adequadas para o compartilhamento de conhecimento.

Outro fator com baixo desempenho pelos mentorados foi a existência de avaliação do programa de mentoria, com RM de 3,6 e percentual de concordantes de 73\%. Para 23\% dos mentorados, não há uma avaliação do progresso obtido nos encontros entre mentores e mentorados. Esses números são preocupantes na medida em que, não havendo monitoramento do programa, problemas que podem ser tratados durante ele sejam percebidos apenas no final, quando não poderão mais ser tratados. Na visão de Tonet e Paz (2006), a organização deveria planejar ações mitigadoras como avaliações periódicas para evitar problemas no compartilhamento de conhecimento.

O fator "Mentoria reversa", com RM de 3,8 e percentual de concordantes de 73\%, também fez parte dos fatores que menos contribuíram entre os mentorados na fase de implementação. Os valores baixos não devem preocupar a organização, pois, no processo de compartilhamento de conhecimento definido, não fazia parte dos objetivos do programa a chamada mentoria reversa, que, segundo Monte (2011), acontece quando uma pessoa menos experiente ensina uma pessoa mais experiente, por exemplo, no caso da expertise em tecnologias da informação.

\subsection{DIAGNÓSTICO DA FASE DE APOIO}

Conforme apresentado nas Tabelas 1 e 2, os valores de 4,4 para RM e de $89 \%$ de concordantes para os mentores, e de 4,2 para RM e de 82\% de concordantes para os mentorados na fase de apoio representam valores aceitáveis para o compartilhamento de conhecimento. Esses resultados e os da Tabela 7 demonstram que houve apoio do mentor ao mentorado nas primeiras tentativas de uso do conhecimento por parte deste, 
e tanto na percepção dos mentores quanto dos mentorados o conhecimento compartilhado foi assimilado por estes últimos.

Tabela 7 - Fatores que mais contribuíram na fase de apoio

\begin{tabular}{|c|c|c|c|c|}
\hline \multirow{2}{*}{ Fator } & \multicolumn{2}{|c|}{ Mentor } & \multicolumn{2}{|c|}{ Mentorado } \\
\hline & $\mathbf{R M}$ & Concordantes & $\mathbf{R M}$ & Concordantes \\
\hline $\begin{array}{l}\text { Liderança não obstaculizou o apoio do } \\
\text { mentor ao mentorado. }\end{array}$ & 4,7 & $100 \%$ & & \\
\hline $\begin{array}{l}\text { Foi possível apoiar o mentorado no exerci- } \\
\text { tamento da prática. }\end{array}$ & 4,6 & $93 \%$ & & \\
\hline $\begin{array}{l}\text { Conhecimento compartilhado foi assimila- } \\
\text { do pelo mentorado. }\end{array}$ & 4,4 & $87 \%$ & 4,7 & $100 \%$ \\
\hline $\begin{array}{l}\text { Teve acesso ao mentor para retirar dúvidas } \\
\text { ou ajudar no exercitamento da prática. }\end{array}$ & & & 4,8 & $100 \%$ \\
\hline
\end{tabular}

Na percepção dos mentorados, com RM de 4,8 e percentual de 100\% de concordantes, o fator "Teve acesso ao mentor para retirar dúvidas ou ajudar no exercitamento da prática” obteve o resultado mais relevante, revelando que há tolerância entre mentores e mentorados sobre possíveis erros na aplicação de conhecimento novo.

Em relação aos mentores, o fator "Liderança não obstaculizou o apoio do mentor ao mentorado" apresentou o resultado mais expressivo, com RM de 4,7 e percentual de concordantes de $100 \%$. Em um programa de mentoria formal, as etapas são bem-definidas, porém, nem sempre o que foi planejado é executado. Por isso, contar com o apoio das lideranças é determinante para apoiar o mentorado nos seus primeiros passos, contribuindo para que ele possa superar as barreiras ao compartilhamento de conhecimento e à incorporação do conhecimento no dia a dia para a resolução dos problemas.

Outro fator bem-avaliado pelos mentores é "Foi possível apoiar o mentorado no exercitamento da prática”, pois apresentou resultado de 4,6 para RM e 93\% de concordantes. A importância desse fator é ressaltado por Kram (1988), ao afirmar que uma das finalidades da mentoria é fazer com que o mentor possa apoiar o mentorado para que este alcance os resultados esperados pela organização.

O fator "Conhecimento compartilhado foi assimilado pelo mentorado" apresentou resultado de 4,4 para RM e $87 \%$ de concordantes para os mentores, e de 4,7 para RM e $100 \%$ de concordantes para os mentorados. Nesse item também se observou que a concordância dos mentores foi maior que a dos mentorados, atingindo o valor máximo, ou seja, 100\%. Analisados nas perspectivas de quem transferiu e de quem recebeu o conhecimento, os resultados foram importantes para aferir o êxito do 
programa formal implantado, pois conforme Salgues (2016), a formalidade do programa propicia o engajamento dos atores.

Tabela 8 - Fatores que menos contribuíram na fase de apoio

\begin{tabular}{lcr}
\multicolumn{1}{c}{ Fator } & \multicolumn{2}{c}{ Mentorado } \\
& RM & Concordantes \\
\hline A mentoria trouxe direcionamentos para a carreira. & 3,3 & $45 \%$ \\
$\begin{array}{l}\text { Substituição de conhecimentos antigos por conhecimentos adquiridos } \\
\text { no programa. }\end{array}$ & 3,8 & $68 \%$ \\
\hline Fonte: os autores. & & \\
\end{tabular}

Em relação aos fatores que menos contribuíram na fase de apoio, na percepção dos mentores todos os fatores tiveram RM superior a 4, motivo pelo qual não serão analisados; no entanto, em relação aos mentores, dois fatores ficaram abaixo de 4. O primeiro "A mentoria trouxe direcionamento para carreira do mentorado" apresentou resultado com RM de 3,8 e percentual de concordantes de 45\%. Em outro contexto, o resultado poderia ser preocupante, mas, no caso em estudo, foi esperado, pois nos moldes em que o programa de mentoria foi planejado os mentorados já ocupam os mesmos cargos dos mentores, mas em níveis inferiores. Nesse caso, não se aplica a afirmativa de Kram (1988) de que um mentorado que não tenha avanço na carreira insinua um baixo desempenho do mentor nessa função.

O segundo fator "Substituição de conhecimentos antigos por conhecimentos adquiridos no programa” apresentou resultado com RM de 3,8 e percentual de concordantes de 68\%. Esses resultados também não foram considerados preocupantes, pois no momento em que a pesquisa com os mentorados foi realizada, aproximadamente um ano após a conclusão do programa de mentoria, a aplicação do conhecimento compartilhado ainda estava sendo assimilada por eles de forma gradual ou imediata, o que coaduna com Tonet e Paz (2006). Em alguns casos, a substituição das práticas será imediata, já em outros a prática do conhecimento compartilhado vai conviver com práticas já dominadas pelo mentorado, até que ocorra a substituição total.

\subsection{DIAGNÓSTICO DA FASE DE INCORPORAÇÃO}

Como essa fase é referente à prática do conhecimento assimilado e este é inerente aos mentorados, não foi aplicada pesquisa com os mentores. Conforme a Tabela 
2, os valores 4,0 de RM e 74\% de concordantes representam valores aceitáveis para o compartilhamento de conhecimento nessa fase do modelo. Esses resultados e os da Tabela 9 demonstram que foram evidenciados poucos obstáculos, ou desafios, para a aplicação do conhecimento.

Tabela 9 - Fatores que mais contribuíram na fase de incorporação

\begin{tabular}{lrl}
\hline \multicolumn{1}{c}{ Fator } & Mentorado \\
& RM & Concordantes \\
\hline $\begin{array}{l}\text { Não houve mudança das atividades, consequentemente o conhecimento com- } \\
\text { partilhado pôde ser aplicado. }\end{array}$ & 4,5 & $100 \%$ \\
\hline $\begin{array}{l}\text { Não foram repassadas novas atividades com sobrecarga de trabalho, dificultan- } \\
\text { do o uso do conhecimento adquirido. }\end{array}$ & 4,4 & $95 \%$ \\
$\begin{array}{l}\text { Os objetivos propostos pelo programa, referente ao compartilhamento de co- } \\
\text { nhecimento, foram atingidos. }\end{array}$ & 4,4 & $86 \%$ \\
\hline $\begin{array}{l}\text { Não houve redução no quadro de funcionários em razão do programa de men- } \\
\text { toria. }\end{array}$ & 4,4 & $73 \%$ \\
\hline \begin{tabular}{l} 
Fonte: os autores. \\
\hline
\end{tabular} & & \\
\hline
\end{tabular}

O fator "Não houve mudança das atividades, consequentemente o conhecimento compartilhado pôde ser aplicado" apresentou resultado com RM de 4,5 e percentual de concordantes de $100 \%$. Esse resultado pode ser explicado por não ter havido, no período de um ano, muitas mudanças nas funções ocupadas por mentores e mentorados. Outro fator que contribuiu de forma significativa foi "Não foram repassadas novas atividades com sobrecarga de trabalho, dificultando o uso do conhecimento adquirido”, com RM de 4,4 e percentual de concordantes de 95\%.

Na fase de implementação, descrita anteriormente, o fator sobrecarga de trabalho pouco contribuiu para o compartilhamento, ensejando-se haver um choque na agenda entre as atividades cotidianas e os encontros de mentoria, no entanto, nessa fase, a sobrecarga de trabalho não foi percebida. Segundo Tonet e Paz (2006), a adição de novas atividades nessa fase do processo pode se constituir em uma barreira ao compartilhamento de conhecimento. O fator "Não houve redução no quadro de funcionários em razão do programa de mentoria” apresentou resultado com RM de 4,4 e percentual de concordantes de 73\%. Segundo os autores, a incorporação dos conhecimentos adquiridos pode resultar em redução do quadro ou até mesmo em demissão de funcionários onde o conhecimento está sendo aplicado. Essa situação pode se tornar um obstáculo ao uso do compartilhamento do conhecimento, exigindo por parte da organização um grande esforço para remediá-la. 
Por fim, no que se refere à Tabela 9, o fator “Os objetivos propostos pelo programa, referente ao compartilhamento de conhecimento, foram atingidos” obteve RM de 4,4 e percentual de concordantes de 86\%; com resultado positivo, pode-se revelar que em relação ao compartilhamento de conhecimento o programa de mentoria implantado foi eficiente na percepção dos mentores.

Tabela 10 - Fatores que menos contribuíram na fase de incorporação

\begin{tabular}{lrr}
\hline \multicolumn{1}{c}{ Fator } & \multicolumn{2}{c}{ Mentorado } \\
& RM & Concordantes \\
\hline $\begin{array}{l}\text { Expectativas de promoção ou melhoria salarial não realizadas. } \\
\text { Liderança acredita nas vantagens e benefícios ao uso do conhecimento } \\
\text { adquirido. }\end{array}$ & 2,6 & $23 \%$ \\
\hline Fonte: os autores. & $30 \%$ \\
\hline
\end{tabular}

O fator "Expectativas de promoção ou melhoria salarial não realizadas", com RM de 2,6 e percentual de concordantes de 23\%, apresentou o pior resultado da pesquisa. Expectativas não previstas de promoção ou de diferenciação salarial em decorrência do uso do novo conhecimento constituem uma barreira ao compartilhamento de conhecimento segundo Tonet e Paz (2006). Nesse sentido, na visão de Kram (1988), ao ter um bom desempenho no programa de mentoria, o mentorado cria uma expectativa de que o mentor possa solicitar à liderança uma promoção para ele. Os baixos valores auferidos levantam um paradoxo, visto que, nas organizações públicas, mesmo as de Sociedade de Economia Mista, seus empregados sabem que as promoções e melhorias salarias obedecem a regras procedimentais.

Por fim, o fator "A liderança acredita nas vantagens e benefícios ao uso do conhecimento adquirido” apresentou resultado com RM de 3,5 e percentual de concordantes de 50\%. Analisando-se todos os fatores relacionados à liderança na pesquisa, percebeu-se que apenas esse fator apresentou resultado abaixo de 4,0. Na fase de iniciação, a questão sobre o apoio da liderança para a participação dos atores no programa de mentoria apresentou valores de RM acima de 4,1 e percentual de concordantes de $80 \%$. Os bons resultados se repetiram na fase de implementação sobre o apoio das lideranças aos encontros de mentoria, com valores de RM acima de 4,0 e percentual de concordantes acima de $80 \%$; e, na fase de apoio, sobre o patrocínio da liderança ao apoio do mentor ao mentorado no uso do conhecimento, obteve-se RM acima de 4,1 e percentual de concordantes acima de $82 \%$. 
Verificou-se, portanto, que a liderança apoiou ou contribuiu com a mentoria em todas as fases, provavelmente por se tratar de um processo formal da empresa, porém, os dados revelam que esses mesmos líderes não acreditam nas vantagens do programa. Como o programa pesquisado foi pioneiro, com pouco mais de um ano implantado, acredita-se em um resultado mais confiável conforme seu amadurecimento.

\section{CONSIDERAÇÕES FINAIS}

O objetivo principal com este trabalho foi analisar a percepção de mentores e mentorados de uma empresa pública de energia sobre o processo de compartilhamento de conhecimento em um programa de mentoria implantado.

Nesse sentido, por meio do modelo teórico utilizado, observou-se que as necessidades de compartilhamento de conhecimento foram bem-definidas pela organização, destacando-se o vínculo com suas estratégias e que as fontes e destinatários foram selecionados de acordo com o que apregoa um programa de mentoria formal. A organização precisaria atentar para a comunicação de seus projetos e programas, visto que possui prêmios na área de Gestão de Conhecimento e o fator cultura de compartilhamento de conhecimento apresentou baixo resultado.

Em relação a averiguar como são estabelecidos os vínculos entre mentores e mentorados na implementação do processo de compartilhamento de conhecimento, concluiu-se que a interação entre mentores e mentorados ocorreu de forma fluida, favorecendo o estabelecimento de vínculo entre as partes. Contribuíram de forma positiva fatores que estão mais presentes na mentoria informal, como os laços de confiança. Como ponto de atenção, ressalvou-se o fator sobrecarga de atividades que, na percepção dos mentorados, constituiu-se em uma barreira ao compartilhamento de conhecimento.

Quanto a verificar como acontece o apoio nas primeiras tentativas de aplicação do conhecimento compartilhado, observou-se que o mentorado foi assistido pelo mentor nos seus primeiros passos de uso do conhecimento compartilhado, bem como foi percebido pelos atores do programa de mentoria que o conhecimento compartilhado foi assimilado. Nenhum ponto de atenção foi evidenciado para esse objetivo, visto que os baixos resultados obtidos estão sob controle. Em relação ao quarto objetivo específico, verificar como acontece a incorporação do conhecimento compartilhado, concluiu-se que não foram evidenciados obstáculos ao uso do conhecimento compartilhado, favorecendo, assim, a incorporação dele pelo mentorado. 
Dois pontos mereceram destaque: o primeiro e positivo foi que na percepção dos mentorados os objetivos do programa de mentoria em relação ao compartilhamento de conhecimento foram alcançados; e o segundo foi em relação ao baixo resultado das expectativas de desenvolvimento das carreiras dos mentorados, necessitando, dessa forma, de um aprofundamento no assunto.

As limitações da pesquisa repousaram no fato de ter foco apenas em uma diretoria/unidade da organização pesquisada. Portanto, sugerem-se futuros estudos para pesquisar a evolução das carreiras dos participantes dos programas na empresa em todo o Brasil.

\section{REFERÊNCIAS}

ALBANAES, P.; SOARES, F. M. de S.; BARDAGI, M. P. Programas de tutoría y mentoría en universidades brasileñas: un estudio bibliométrico. Revista de Psicología, v. 33, n. 1, 2015.

ALMEIDA, N. C. P. de; SOUZA-SILVA, J. C. de. O que é isso? Como os construtos de aprendizagem organizacional socioprática, comunidades de prática e mentoria são compreendidos na visão de executivos da organização Alpha. Revista Administração em Diálogo, v. 17, n. 2, p. 211-235, 2015.

ANDRADE, D. C. T. de et al. Táticas organizacionais; desenvolvimentista; conteúdos e informação; tendências integradoras: a socialização organizacional abordada sob quatro correntes distintas. Revista da Universidade Vale do Rio Verde, Três Corações, v. 10, n. 2, p. 239-250, 2012.

BATISTA, F. F. Gestão do conhecimento na administração pública: Resultados da pesquisa IPEA 2014-Grau de externalização e formalização. Brasília, DF: Instituto de Pesquisa Econômica Aplicada, 2015. Disponível em: <http://ipea.gov.br/portal/ images/stories/PDFs/TDs/td_2066a.pdf>. Acesso em: 10 jul. 2017.

BELL, C. R. Mentor e Aprendiz. 6. ed. São Paulo: M. Books. 2005.

BELO, A. C. C.; ACCIOLY, S. A mentoria como influência de pessoas no ambiente organizacional. Ciências humanas e sociais, v. 3, n. 1, p. 185-200, 2015.

BERNHOEFT, R. E. A. Mentoring: abrindo horizontes, superando limites, construindo caminhos. São Paulo: Gente, 2001.

BERTALANFLY, L. V. Teoria geral de sistemas. 2. ed. Petrópolis: Vozes, 1975. 
BORGES, L. de O.; ALBUQUERQUE, F. J. B. de. Socialização Organizacional. In: ZANELLI, J. C.; BORGES-BITTENCOURT, J. E.; BASTOS, A. V. B. (Org.). Psicologia, Organizações e Trabalho no Brasil. Artmed: Porto Alegre, 2004.

BORGES, L. de O.; CARVALHO, V. D. Tutorização Organizacional de Novos Empregados. In: BORGES, L. de O.; MOURÃO, L. (Org.). O Trabalho e as Organizações: Atuações a partir da psicologia. Artmed: Porto Alegre, 2013.

BOZIONELOS, N. et al. Employability and Job Performance as Links in the Relationship Between Mentoring Receipt and Career Success: A Study in SMEs. Group \& Organization Management, v. 41, i. 2, 2016.

BRITO-DE-JESUS, K. C. et al. Desenvolvimento de Competências Gerenciais de Gestores Públicos em Instituições Federais de Educação. Revista Interdisciplinar de gestão social, v. 5, n. 1, p. 37- 60, 2014.

BRITO, L. M. P. Gestão de competências, Gestão do Conhecimento e organizações de aprendizagem: instrumento de apropriação pelo capital do saber. Fortaleza: UFC, 2005.

BRUNO-FARIA, F.; VARGAS, E. R. de. Inovação, criatividade e empreendedorismo. Rev. Psicol., Organ. Trab., v. 13, n. 3, p. 5-6, set./dez. 2013. Dossiê Editorial.

CASTRO, A. B. C. de; BRITO, L. M. P.; VARELA, J. H. de S. A ressignificação da área de gestão de pessoas e os novos papéis das pessoas e das organizações. HOLOS, v. 4, p. 408-423, 2017.

DOS-SANTOS, M. G. et al. Aprendizagem organizacional e suas modalidades: desenvolvendo a habilidade interpessoal nos programas trainees. Revista de Administração FACES Journal, v. 14, n. 3, p. 95-113, 2015.

FREIRE, P. de S. et al. Corporate University Network: Initial Considerations for a New Model of Corporate Education. Revista ESPACIOS, v. 37, i. 5, 2016.

FUKUNAGA, F. et al. Indicadores bibliometricos da produção acadêmica mundial sobre o conceito do trabalhador do conhecimento. Perspectivas em Gestão \& Conhecimento, João Pessoa, v. 5, p. 42-56, out. 2015. Edição Especial.

GABRIEL, M. L. D. Métodos Quantitativos em Ciências Sociais. Sugestões para Elaboração do Relatório de Pesquisa. Desenvolvimento em Questão, v. 12, n. 28, 2014. 
GODOY, A. S. Pesquisa qualitativa: tipos fundamentais. Revista de Administração de Empresas, v. 35, n. 3, p. 20-29, 1995.

GUPTAN, S. U. Mentoring: a practitioner's guide to touching lives. New Delhi: Response Books, 2006.

KIANTO, A. et al. The interaction of intellectual capital assets and knowledge management practices in organizational value creation. Journal of Intellectual Capital, v. 15, i. 3, p. 362-375, 2014.

KRAM, K. E. Mentoring at work: developmental relationships in organizational life. Lanham: University Press of America, 1988.

LAHTI, R. K.; BEYERLEIN, M. M. Knowledge transfer and management consulting: A look at “The firm”. Business Horizons, v. 43, i. 1, p. 65-74, 2000.

LIKERT, R. A technique for the measurement of attitudes. Archives of psychology, 1932.

MALHOTRA, N. K. Pesquisa de Marketing: uma orientação aplicada. Porto Alegre: Bookman, 2001.

MARQUES, F. Gestão de Pessoas: fundamentos e tendências. Brasília, DF: DDG/ ENAP, 2015.

MERRIAM, S. Qualitative Research and Case Study Applications in Education. San Francisco: Jossey-Bass, 1998.

MONTE, G. T. do. Prática da mentoria: Estudo de caso no Instituto Federal de Educação, Ciência e Tecnologia do RN. 2011. 103 p. Dissertação (Mestrado em Administração)-Universidade Potiguar, Natal, 2011.

NOE, R. A. An investigation of the determinants of successful assigned mentoring relationships. Personnel Psychology, v. 41, i. 3, p. 457-479, 1988.

OLIVEIRA, J. A. de; CASTRO, A. B. C. de; BRITO, L. M. P. Gestão do Conhecimento: um estudo em um hospital federal universitário do Nordeste do Brasil. Revista Gestão \& Conhecimento, v. 10, n. 2, p. 1-29, 2016.

PORTUGAL, J. M. A. C. N. Efeitos na inclusão social percebidos pelos participantes num programa de mentoria: o caso do PENDULUM. 2016. 110 p. Dissertação (Mestrado em Economia Social e Solidária)-Instituto Universitário de Lisboa, 2016. Disponível em: <https://repositorio.iscteiul.pt/bitstream/10071/13639/1/2016Dissertacao_JoanaPortugal.pdf>. Acesso em: 07 jul. 2017. 


\section{QUANDT, C. Institucionalização da Gestão do Conhecimento na Admin-} istração Pública: Estágio Atual e Desafios Futuros. Seminário Ipea, 2014. Disponível em: <http://repositorio.ipea.gov.br/bitstream/11058/3177/1/Apresenta\%C3\%A7\%C3\%A3o_Carlos\%2bQuandt\%20Modo\%20de\%20Compatibilidade. pdf>. Acesso em: 11 jul. 2017.

REALI, A. M. de M. R.; TANCREDI, R. M. S. P.; MIZUKAMI, M. da G. N. Programa de Mentoria On-line para professores iniciantes: fases de um processo. Cadernos de Pesquisa, v. 40, n. 140, p. 479-506, maio/ago. 2010.

SALGUES, L. J. de V. Programas de mentoria formal: o conhecimento como diferencial competitivo. 2016. 241 p. Tese (Doutorado em Gestão)-Universidade de Trásos-Montes e Alto Douro, Vila Real, Portugal, 2016. Disponível em: <http://repositorio. utad.pt/bitstream/10348/5740/1/phd_ljvsalgues.pdf>. Acesso em: 05 jul. 2017.

SANTOS, B. A. Coaching e mentoring como práticas de compartilhamento do conhecimento: estudos de casos em empresas públicas paulistas. 2015. 139 p. Dissertação (Mestrado em Administração)-Universidade Metodista de São Paulo, 2015. Disponível em: <http://tede.metodista.br/jspui/handle/tede/1473>. Acesso em: 08 jul. 2017.

SCANDURA, T. A. Dysfunctional mentoring relationships and outcomes. Journal of Management, v. 24, i. 3, p. 449-467, June 1998.

SCULLY, R.; KHOSROWSHAHI, F. Implementing the Process of Knowledge Sharing for Small Construction Consultant Practices in Ireland'. International Journal of The Built \& Human Environment Review, v. 4, i. 1, p. 45-58, 2011.

SHEA, G. F. Mentoring: como desenvolver o comportamento bem-sucedido do mentor. Rio de Janeiro: Qualitymark, 2001.

SHEA, G. F. The mentoring organization. Califórna: Crisp Publication, 2003.

SILVA, A. M.; SOUZA-SILVA, J. C. de. Aprendizagem e formação de sucessores na empresa familiar: um estudo de caso da Loja Menezes. Revista Administração em Diálogo, v. 17, n. 1, p. 118-145, jan./abr. 2015.

STRAUHS, F. do R. et al. Gestão do Conhecimento nas Organizações. Curitiba: Aymará Educação, 2012. 
STRAUS, S. E. et al. Characteristics of Successful and Failed Mentoring Relationships: A Qualitative Study Across Two Academic Health Centers. Acad Med., v. 8, i. 1, p. 82-89, Jan. 2013.

TONET, H. C.; PAZ, M. das G. T. da. Um modelo para o compartilhamento de conhecimento no trabalho. Revista de Administração Contemporânea, v. 10, n. 2, p. 75-94, 2006.

TRIBUNAL DE CONTAS DA UNIÃO. Governança e Gestão de Pessoas em Unidades da Administração Pública Federal. Levantamento/Relatório. Brasília, DF: SEFIP, 2013.

TROTTA, A. A. C. et al. ¿Cómo asegurar un buen feedback en el proceso tutorial? Revista CIDUI, n. 2, 2014.

VERGARA, S. C. Projetos e relatórios de pesquisa em Administração. 13. ed. São Paulo: Atlas, 2011.

WANG, S.; NOE, R. A. Knowledge sharing: A review and directions for future research. Human Resource Management Review, v. 20, p. 115-131, 2010.

YIN, R. K. Estudo de Caso: planejamento e métodos. 4. ed. Porto Alegre: Bookman, 2010.

\section{Como citar este artigo:}

\section{ABNT}

BRITO, Lydia Maria Pinto Brito et al. Programa de mentoria: uma estratégia seminal de compartilhamento do conhecimento em uma empresa pública de energia.

RACE, Revista de Administração, Contabilidade e Economia, Joaçaba: Ed. Unoesc, v. 16, n. 3, p. 209-234, 2017. Edição Especial. Disponível em: <http://editora. unoesc.edu.br/index.php/race>. Acesso em: dia/mês/ano.

\section{APA}

Brito, L. M. P. B., Silva, A. S. da, Castro, A. B. C. de, Gurgel, F. F., \& Varela, J. H. de S. (2017). Programa de mentoria: uma estratégia seminal de compartilhamento do conhecimento em uma empresa pública de energia [E. especial]. RACE, Revista de Administração, Contabilidade e Economia, 16(3), 209-234. Recuperado em dia/mês/ ano, de http://editora.unoesc.edu.br/index.php/race 